https://helda.helsinki.fi

\title{
Polydomy (Polycaly)
}

\section{Sundström, Liselotte}

Springer

2019

Sundström , L 2019 , Polydomy (Polycaly) . in C K Starr (ed.) , Encyclopedia of Social

pÿlnsects . Springer , Cham , pp. 745749 . https://doi.org/10.1007/978-3-319-90306-4_98-1

http://hdl.handle.net/10138/334262

https://doi.org/10.1007/978-3-319-90306-4_98-1

unspecified

acceptedVersion

Downloaded from Helda, University of Helsinki institutional repository.

This is an electronic reprint of the original article.

This reprint may differ from the original in pagination and typographic detail.

Please cite the original version. 
Polydomy (Polycaly)

Liselotte Sundström

Faculty of Biological and Environmental Sciences

University of Helsinki, Finland

Email: Liselotte.sundstrom@helsinki.fi

(C) Springer Nature Switzerland AG 2019

C. Starr (ed.), Encyclopedia of Social Insects,

https://doi.org/10.1007/978-3-319-90306-4_98-1

\section{Synonyms}

Multi-nest colonies; Multiple nests; Polycaly

As a rule, social insect colonies occupy a single nest throughout the colony cycle, but in many species of ants a colony can also simultaneously occupy multiple nests. This may ensue following nest relocation or represent a more permanent nesting strategy. Social insect colonies are defined as polydomous when they simultaneously occupy multiple, spatially separated nest sites. The antonym is monodomy, which is the commonly perceived mode in which colonies occupy a single nest site. The terms monodomy and polydomy originate from the Greek word "domos" for house, with the additional qualification for one (mono) and many (poly). The terms "polycaly" and "polydomy" were first introduced by Auguste Forel (9) to define multi-nest societies of two different types, although later work has often used the two terms interchangeably. Forel defined polycaly as "an arrangement of an ant colony in several nests, each containing a more or less independent population necessarily constituted by brood, workers and one or several reproductive female(s)" and reserved the term polydomy for “...other colonies lacking either brood or a queen” (5). Debout et al. (5) propose that the term polydomy be used when referring to “...purely spatial and genetic proximity between several nests, whereas polycaly may be kept, where convenient, to refer to observed non-aggressive behavioural interactions between nests of a polydomous colony.". An overview of the wealth of terms used to define aspects of polydomy can be found in (5). Today these definitions are used interchangeably, such that some make distinctions, which do not exactly follow Forel's definition. For the present purpose, these are treated as equivalent.

Polydomy/polycaly was first described by Auguste Forel (9) in the genus Formica. In his definition, polydomy does not include the requirement that queen(s) and/or brood should be present in all nests, while polycaly does include this condition. Thus, his definition classifies as polydomous many ant species that do establish intermittent "foraging" nests, which serve as conveyor stations for collecting and storing food and are depopulated after the food is depleted (5). 
Polydomy should not be confused with multicoloniality, which refers to a situation in which multiple monodomous or polydomous colonies inhabit the same habitat patch (16).

Polydomy is usually, but not always, linked to polygyny, the presence of multiple queens in the same colony. Based on the strict definition by Forel (i.e. polycaly) monogyne colonies (single queen per colony) cannot be polydomous, whereas this is possible under the more relaxed definition, which requires each nest to contain either brood or breeding individuals (queens or fertile workers). Indeed, many monogyne species may inhabit multiple nests, i.e. be polydomous, but would not be polycalous. In this case, a queen would be present in only one of the nests, but brood may be distributed across several nests (5). In this case, the defining trait is functional unity.

Polydomy, sensu Debout et al. (5), has only been described in ants and termites (5), although satellite nests have been described also in the paper wasp Polistes fuscatus (13), and extensive drifting of workers among nests has been described in the wasp Polistes canadensis (19). In ants, polydomous species have been described in most subfamilies, but it is especially common, and well studied in the three largest subfamilies Dolichoderinae, Formicinae and Myrmicinae. In termites, polydomy has been recorded in two tribes, the Nasutitermitinae and Reticulitermitinae (5). Polydomy may be permanent, with a transient phase starting from one founding nest that gives rise to new bud nests, facultative, such that a species may have either monodomous or polydomous colonies, and/or periodical, with colonies inhabiting multiple nests only e.g. seasonally. In some species, such as Formica yessensis, Formica paralugubris, and Linepithema humile, polydomous colonies expand to form supercolonies.

\section{Benefits and drivers of polydomy}

Polydomy as a permanent nesting strategy is almost entirely restricted to ants, and termites. In most cases, polydomy is associated with the presence of multiple reproductive queens (polygyny). Thus similar selection regimes may apply to both traits. Polygyny is considered to be driven by high dispersal risks in conjunction with adaptation to patchy habitats and habitat crowding, which favors local dispersal and the formation of bud nests near the maternal colony (10, 11). Consequently, the close proximity of mother and daughter queens may facilitate the maintenance of contact with the natal nest, especially given their genetic ties, which may lead to more or less permanent multi-nest societies. Polygyny is, however, also common in wasps, and cannot therefore alone explain the almost unique occurrence of polydomy in ants and termites. It remains to be seen whether polydomy occurs in social spiders, aphids, or thrips. One main driver, in conjunction with polygyny, may be that the worker individuals of ants and termites are wingless, in contrast to most other social insects, such as bees and wasps. This considerably restricts the area 
that an individual worker can cover during foraging, and given that social insects are central place foragers, may be a crucial mechanism that allows expanding foraging grounds, and colony territory by establishing remote nest units $(5,16)$. The occupation of multiple nest sites allows exploration and exploitation of a larger area on foot, because resources can be stored in the satellite nests, and brood brought to these. As brood in principle only needs to be transported once, this will reduce the overall energy and time needed to distribute food and other resources to immobile offspring.

A dispersed distribution of nests also confers other benefits per se. Having nest units distributed across the entire habitat patch will create a competitive advantage over both other species and con-specific competitors, and thus aid the monopolization of a patch $(5,16)$. This also allows dividing the workforce and brood across multiple units, and thus the maintenance of a larger overall work force. A larger work force will add further competitive advantage, and the distribution of the work force into smaller units may confer efficiency benefits, as the per capita work efficiency and flexibility generally is higher in smaller units (16 and references therein). The distribution of the work force across multiple nests will also allow a more efficient utilization of periodically abundant resources, and can alleviate space constraints $(5,16)$. For example, the cavity-dwelling ant Temnothorax rugulatus turns to polydomy when worker density within the nest exceeds a certain limit (4). Moreover, spreading queens, brood, and workers across separate units also confers bethedging benefits, as this reduces the risk of colony mortality due to attacks by predators or other environmental hazards that may lead to the loss of queens, and workers.

\section{Facultative, seasonal and permanent polydomy}

Polydomy is an evolutionarily labile trait, found in many taxa, and highly variable both across and within species. A common environmental link is that the habitat is patchy both in time and space, with polydomy being favored both in stable, but fragmented habitats, and in habitats under frequent perturbation and destruction. Polydomy may be permanent, in which case a mature colony continuously inhabits multiple nest sites. New colonies are, however, founded by single queens or a group of queens, and therefore initially inhabit a single nest. Polydomy may also be facultative, in which case some colonies become polydomous, whereas others remain monodomous throughout the colony life cycle. This phenomenon is often linked to within-species variation in queen number (i.e. facultative polygyny). For example, the wood ants Formica truncorum and $F$. exsecta come in two forms, a) monogyne and monodomous, and b) polygyne and polydomous (20). In other species, such as the genus Myrmica, the variation in queen number and nest number is more continuous, and often linked to the age of the colony (20). 
Polydomy can also be seasonal, such that the same colony periodically inhabits either a single, or multiple nest site(s). For example, the polydomous colonies of $F$. truncorum converge into one or a few hibernation nest(s) during winter, and migrate via massive trails to settle into 50 or more summer nests (much like Finnish people do to their summer houses) $(8,17)$. In this way the species can come to monopolize entire archipelago islands up to $0.05 \mathrm{~km}^{2}$, keeping away both humans, and most other ant species. Seasonal polydomy also occurs in monogyne species, mainly driven by foraging ecology when food resources are unpredictable in space and time ( 5 and references therein). This may be directly linked to ergonomic aspects, which arise from a rush to exploit resources under food bonanzas, and the costs of traveling long distances. Establishing nests at intermediate distances from the resource allows the ants to quickly collect the food and put it in safe storage until consumption or later transfer to the main nest. Finally, workers may establish satellite nests to evade queen control over reproduction. In many species, workers can lay maledestined eggs, but the close presence of queens may inhibit this behavior. In queenless remote units this influence disappears, and the workers may gain direct fitness benefits - in particular if the colony has only a single queen $(1,18)$.

Polydomy clearly confers a suite of advantages, especially in the light of the limited operative range that applies to the flightless worker ants or termites. This is perhaps best illustrated by the fact that most major invasive species of ants are obligately highly polygyne, and polydomous. These include, the Argentine ant (Linepithema humile), the garden ant (Lasius neglectus), the yellow crazy ant (Anoplolepis gracilipes), and the Pharaoh's ant (Monomorium pharaonis). A few, such as the fire ant (Solenopsis invicta), are facultatively polygyne and polydomous. Surprisingly, the highly polygyne and polydomous mound-building ants of the genus Formica, are not members of this clan, perhaps because of their relatively specialized habitat requirements, and their boreal distribution.

\section{Costs of polydomy}

There are, however, also limitations to the benefits gained by polydomy. For example, when polydomy is associated with patchy and stable habitats, the colony will inevitably outgrow the resources, and come to overexploit them, whereas this is less of a problem for species that inhabit ephemeral habitats under frequent disturbance. Dense populations are also prone to the spread of disease, although polydomy is sometimes presented as a way of evading infections. In fact, if individuals, as per the definition of polydomy, are frequently exchanged between nests, polydomy will only aid the spread of disease. These factors may eventually lead to a population crash. 
Polydomy is also associated with limited dispersal, which may be further emphasized by selection operating in favor of philopatry (20). This will increase the number of breeders in the current patch, whereas long-distance dispersers may be selectively disfavored. If the habitat in the patch is of a transient nature the evolutionary future of the colony is bleak, unless enough propagules have managed to establish new populations elsewhere. Finally, given that polydomous colonies are founded by a small number of individuals, perhaps just one queen, the workers will represent a limited gene pool, and thus be related. Relatedness is a key factor in the evolution of eusociality (2), but as the colony grows and new breeders are added competition among colony members will increase, which may oust the benefits of kin selected cooperation (15). A common notion is that inbreeding will increase over time, followed by a suite of potential disadvantages caused by inbreeding depression. This is, however, not necessarily the case. When new queens are added over time, while old ones die, the genetic diversity in polygyne and polydomous populations will not erode, and as long as mating is random across the entire colony, homozygosity for deleterious alleles will not increase beyond that expected under a limited population size. Furthermore, immigrating males, which mate with the new queens, may bring in new genetic material. The situation may change if genetically separated enclaves arise and/or if the number of breeders declines.

\section{Measuring polydomy}

Given that selection can act on social groups at multiple levels, e.g. between individuals within a colony, and between separate colonies (3), determining the boundaries of a colony, and knowing which individuals are part of the same colony is vital for understanding how selection acts within a population of social insect colonies (7). H.C. McCook was the first to point this out (12). This cannot be determined without a more detailed analysis based on three approaches, preferably together: analysis of the genetic structure of the population, behavioral observations on antagonistic reactions, and the analysis of trail networks and resource sharing. Genetic markers, and behavioral analysis of antagonistic relationships between nests are useful for assessing shared colony membership vs. colony boundaries, but do not reflect ongoing interactions between individual nests $(5,14)$. For example, a set of nests may be genetically indistinguishable, but this does not mean that they actively cooperate by exchanging resources. Direct observations on worker exchange via trails between nests, and/or by mark-recapture are needed to reveal ongoing interactions between nests $(6,7,16)$.

\section{References}


1. Banschbach VS, Herbers JM. 1996. Complex colony structure in social insects. II. Reproduction, queen-worker conflict, and levels of selection. Evolution 50, 298-307

2. Boomsma JJ. 2013. Beyond promiscuity: mate-choice commitments in social breeding. Phil. Trans, Roy. Soc. B. 368 (1613), Special Issue SI DOI 10.1098/rstb.2012.0050

3. Bourke AFG, Franks, NR. 1995. Social Evolution in Ants. Monographs in Behaviour and Ecology, Princeton Academic Press 529pp.

4. Cao TT. 2013. High social density increases foraging and scouting rates and induces polydomy in Temnothorax ants. Behavioral Ecology and Sociobiology 67, 1799-1807.

5. Debout G, Schatz B, Elias M, McKey D. 2007_Polydomy in ants: what we know, what we think we know, and what remains to be done. Biol. J. Linn Soc. 90(2), 319-348

6. Ellis S, Robinson EJH. 2014. Polydomy in red wood ants. Insect Soc 61, 111-122.

7. Ellis S, Procter DS, Buckham-Bonnet P, Robinson EJH. 2017. Inferring polydomy: a review of functional, spatial and genetic methods for identifying colony boundaries. Insect. Soc. 64, 19-37, DOI 10.1007/s00040-016-0534-7

8. Elias M, Rosengren R, Sundström L. 2005. Seasonal polydomy and unicoloniality in a polygynous population of the ant Formica truncorum. Behav. Ecol. Sociobiol. 57, 339-349

9. Forel A. 1874. Les fourmis de la Suisse. Systématique, notices anatomiques et physiologiques, architecture, distribution géographique, nouvelles expériences et observations de moeurs. Neue Denkschriften der Allgemeinen Schweizerischen Gesellschaft der Gesammten Naturwissenschaften 26: 1-452.

10. Hakala SM, Seppä P, Helanterä H. 2019 - 2019. Evolution of dispersal in ants (Hymenoptera: Formicidae): a review on the dispersal strategies of sessile superorganisms Myrmecological News in revision

11. Keller, L. 1995. Social life - the paradox of multiple-queen colonies. Trends in Ecology \& Evolution, 10, 355-360 DOI: 10.1016/S0169-5347(00)89133-8

12. McCook, HC. 1877 Mound-making ants of the Alleghenies, their architecture and habits. Transactions of the Entomological Society of America 6, 253-296

13. Page, RE. Post, DC. Metcalf, RA 1989, Satellite nests, early males, and plasticity of reproductive behavior in a paper wasp. American Naturalist, 134, 731-748

14. Pedersen, JS. Boomsma, JJ. 1999. Genetic analyses of colony structure in polydomous and polygynous ant populations. Biological Journal of the Linnean Society, 66, 115-144.

15. Queller DC. 1994. Genetic relatedness in viscous populations. Evolutionary Ecology, 8, 7073

16. Robinson, EJH. 2014. Polydomy: the organisation and adaptive function of complex nest systems in ants. Current Opinion in Insect Science, 5, 37-43

17. Rosengren, R, Cherix, D. Pamilo, P. 1985. Insular ecology of the red wood ant Formica truncorum Fabr. I. Polydomous nesting, population size and foraging. Mitteilungen der Schweizerischen Entomologischen Gesellschaft 58, 147-175.

18. Snyder. LE. Herbers, JM. 1991. Polydomy and sexual allocation ratios in the ant Myrmica punctiventris. Behavioral Ecology and Sociobiology 28: 409-415.

19. Sumner, S. Lucas, E, Barker, J. Isaac, N. 2007. Radio-Tagging Technology Reveals Extreme Nest-Drifting Behavior in a Eusocial Insect. Current Biology, 17, 140-145 https://doi.org/10.1016/j.cub.2006.11.064

20. Sundström, L. Seppä, P. Pamilo, P. 2005 Genetic population structure and dispersal patterns in Formica ants - a review. Annales Zoologici Fennici 42, 163-177

Synonyms: multi-nest colonies, polycaly 